\title{
Fuzzy Controller Design Using Evolutionary Techniques for Twin Rotor MIMO System: A Comparative Study
}

\author{
H. A. Hashim ${ }^{1}$ and M. A. Abido ${ }^{2}$ \\ ${ }^{1}$ System Engineering Department, King Fahd University of Petroleum and Minerals, Dhahran 31261, Saudi Arabia \\ ${ }^{2}$ Electrical Engineering Department, King Fahd University of Petroleum and Minerals, Dhahran 31261, Saudi Arabia
}

Correspondence should be addressed to M. A. Abido; mabido@kfupm.edu.sa

Received 26 October 2014; Accepted 16 January 2015

Academic Editor: Francois B. Vialatte

Copyright (c) 2015 H. A. Hashim and M. A. Abido. This is an open access article distributed under the Creative Commons Attribution License, which permits unrestricted use, distribution, and reproduction in any medium, provided the original work is properly cited.

\begin{abstract}
This paper presents a comparative study of fuzzy controller design for the twin rotor multi-input multioutput (MIMO) system (TRMS) considering most promising evolutionary techniques. These are gravitational search algorithm (GSA), particle swarm optimization (PSO), artificial bee colony (ABC), and differential evolution (DE). In this study, the gains of four fuzzy proportional derivative $(\mathrm{PD})$ controllers for TRMS have been optimized using the considered techniques. The optimization techniques are developed to identify the optimal control parameters for system stability enhancement, to cancel high nonlinearities in the model, to reduce the coupling effect, and to drive TRMS pitch and yaw angles into the desired tracking trajectory efficiently and accurately. The most effective technique in terms of system response due to different disturbances has been investigated. In this work, it is observed that GSA is the most effective technique in terms of solution quality and convergence speed.
\end{abstract}

\section{Introduction}

In the recent few years, unmanned autonomous vehicles are needed for various applications including Twin Rotor MIMO system (TRMS) which has been studied under many engineering applications including control, modeling, and optimizations. TRMS is emulating the behavior of helicopter dynamics [1] and its main problem can be summarized in solving high nonlinearities in the system in order to provide the desired tracking performance with suitable control signal.

Real coded genetic algorithm, particle swarm, and radial basis neural network are used for TRMS parameter identification without any former knowledge [2-4]. TRMS has been examined with different controllers such as four PID controllers with genetic algorithm to tune PID gains [5], decoupling control using robust dead beat [6], model predictive control [7], and $H_{\infty}$ control for disturbance rejection [8]. All aforementioned controllers are examined under hovering positions and switching LQ controller is used to switch the controller between different operating points [9]. Hybrid fuzzy PID controller shows good tracking performance in comparison to PID controller [10, 11]. Sliding mode control has been proposed in $[12,13]$ where fuzzy control and adaptive rule techniques are used to cancel the system nonlinearities. Both techniques apply integral sliding mode for the vertical part with robust behavior against parameters variations and they showed good results. However, their limitations reflected lie in the control signal and design complexity. Generally, fuzzy logic control (FLC) has been developed as an intelligent control approach for various applications in the presence of uncertainties. Fuzzy has been implemented with fuzzy control for nonlinear systems with unknown dead zone $[14,15]$, for output feedback of nonlinear MIMO systems [15, 16], for uncertain systems [17], and for systems with random time delays [18]. Also, observer based on adaptive fuzzy has been implemented successfully in [19-21]. Decoupling FLC will be used in this work to control TRMS by removing the coupling effect in addition to providing the desired tracking performance.

Evolutionary algorithms are important optimization tools in engineering applications and they are gaining popularity among the researchers. Particle swarm optimization (PSO) 
has been proposed as efficient optimization algorithm [22]. PSO has been successfully implemented in different engineering applications including identifying the path following footstep of humanoid robot [23], setting the control parameters for automatic voltage regulator [24, 25], and designing fuzzy PSO controller for navigating unknown environments [26]. Differential evolution (DE) was formulated as impressive evolutionary algorithm in $[27,28]$. DE was successfully tested for various applications involving tuning multivariable PI and PID controllers of the binary Wood-Berry distillation column [29], optimizing delayed states of Kalman filter for induction motor [30] and optimizing the controller parameters of adaptive neural fuzzy network for nonlinear system [31]. A new optimization technique based on bees swarming was developed [32] and later artificial bee colony (ABC) emerged in [33]. ABC shows great results for many applications, for instance, employing $\mathrm{ABC}$ to find the optimal distributed generation factors for minimizing power losses in an electric network [34], defining the path planning and minimizing the consumption energy for wireless sensor networks [35]. Finally gravitational search algorithm (GSA) was proposed recently as promising evolutionary algorithm and shows impressive results [36]. GSA has been successfully implemented in many areas including fuzzy controller design [37, 38] and solving multiobjective power system optimization problems $[39,40]$.

In this work, the main contribution is proposing a decoupling PD fuzzy control scheme for the nonlinear TRMS. Controller parameters will be defined based on an optimization technique. GSA, PSO, ABC, and DE have been implemented for a comparative study in order to optimize the gains of a proposed controller for the nonlinear TRMS. Another contribution of this work is defining the minimum objective function in addition to finding the most robust technique with different initial populations. These optimization techniques will be used to tune PD gains and coupling coefficients. The proposed approach is investigated for TRMS at different operating conditions taking into account the need for cancelling strong coupling between two rotors and the specific range of control signals, and finally providing the desired tracking response. Generally, the results show the effectiveness of the considered techniques. The best performance was observed with GSA in terms of convergence rate and solution optimality. The paper is organized as follows. Section 2 includes the problem formulation. The proposed control strategy is presented in Section 3. Optimization techniques will be discussed in Section 4. In Section 5, simulation results are presented and discussed and the effectiveness of the proposed approach is demonstrated. Finally, Section 6 concludes the main findings and observations with recommended future work.

\section{Twin Rotor MIMO System Modeling}

Twin rotor is a laboratory setup for stimulating helicopter in terms of high nonlinear dynamics with strong coupling between two rotors and training various control algorithms for angle orientations. The full description of TRMS has been

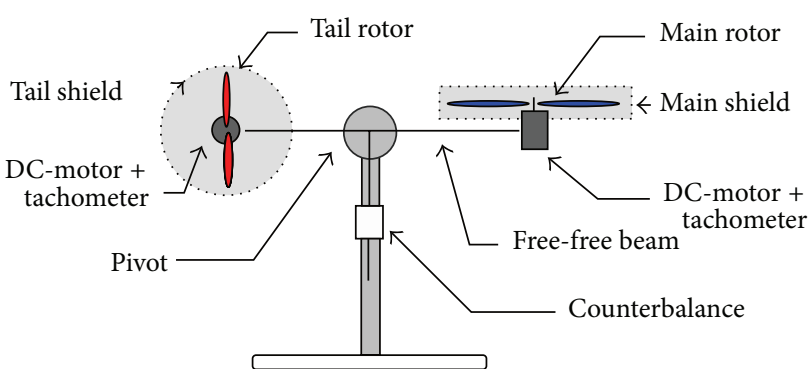

FIGURE 1: TRMS setup.

detailed in [1], where the system has six states defined as $x=\left[x_{1}, x_{2}, x_{3}, x_{4}, x_{5}, x_{6}\right]^{T}$, two control signals $u_{1}$ and $u_{2}$, and finally the output represented by $y=\left[x_{1}, x_{3}\right]^{T}$. The main structure of TRMS studied in this work is shown in Figure 1.

The complete model of the system can be represented as follows:

$$
\begin{gathered}
\frac{d}{d t} x_{1}=x_{2}, \\
\frac{d}{d t} x_{2}=\frac{a_{1}}{I_{1}} x_{5}^{2}+\frac{b_{1}}{I_{1}} x_{5}-\frac{M_{g}}{I_{1}} \sin x_{1} \\
-\frac{B_{1 \psi}}{I_{1}} x_{2}+\frac{0.0326}{I_{1}} \sin \left(2 x_{1}\right) x_{4}^{2} \\
-\frac{K_{g y}}{I_{1}} \cdot\left(a_{1} x_{5}^{2}+b_{1} x_{5}\right) x_{4} \cos x_{1}, \\
\frac{d}{d t} x_{4}=\frac{a_{2}}{I_{2}} x_{6}{ }^{2}+ \\
+\frac{b_{2}}{I_{2}} x_{6}-\frac{B_{1 \varphi}}{I_{2}} x_{4}-1.75 \frac{k_{c}}{I_{2}}\left(a_{1} x_{5}{ }^{2}+b_{1} x_{5}\right), \\
\frac{d}{d t} x_{5}=-\frac{T_{10}}{T_{11}} x_{5}+\frac{k_{1}}{T_{11}} u_{1}, \\
\frac{d}{d t} x_{6}=-\frac{T_{20}}{T_{22}} x_{6}+\frac{k_{2}}{T_{22}} u_{2} .
\end{gathered}
$$

TRMS dynamics are defined by six states as vertical or main angle, yaw or horizontal angle, vertical velocity, yaw velocity, and two momentum torques, respectively. The parameters of TRMS can be defined as follows: $a_{1}, b_{1}, a_{2}$, and $b_{2}$ are constant parameters referring to the static behavior of the system, two moments of inertia for vertical and horizontal rotors are stated as $I_{1}$ and $I_{2}$, friction momentums are $B_{1 \psi}, B_{2 \psi}, B_{1 \varphi}$, and $B_{2 \varphi}$, gravity momentum is $M_{g}$, gyroscopic momentum is $K_{g y}$, other parameters that have to be defined for vertical rotor are $T_{11}, T_{10}$ and for horizontal rotor $T_{22}, T_{20}$, and finally vertical and horizontal rotor gains are $k_{1}$ and $k_{2}$.

The control signals are used to control angles orientations by two torque momentum equations. Strong coupling between two rotors in addition to high nonlinearities detailed in (1) ended to formulate the tracking control as an interesting 


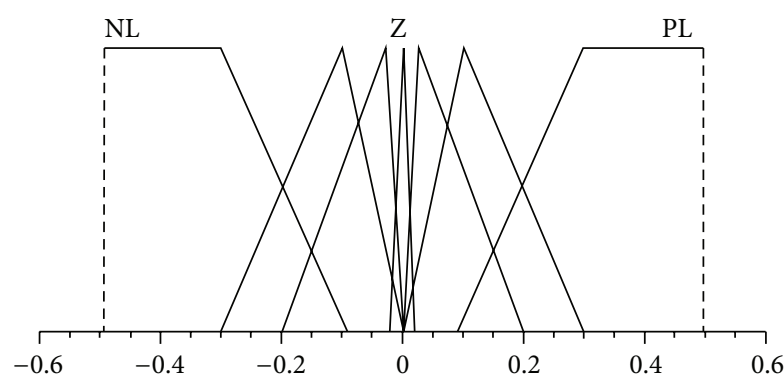

Figure 2: Membership fuctions of horizontal error and error rate.

problem to be investigated. The solution of the control problem will be developed using decoupling proportional derivative fuzzy logic controller (PDFLC).

\section{Proposed Control Approach}

Since last few decades, fuzzy logic control [41] has been used extensively as intelligent technique in many control applications. In this work, decoupling PDFLC is proposed to solve coupling effects and high nonlinearities in addition to providing soft and smooth tracking response. The proposed control should be able to maintain the control signal in the demand range.

3.1. Structure of the Proposed Controllers. The proposed decoupling PDFLC scheme is mainly composed of four fuzzy controllers stated as vertical, horizontal, vertical to horizontal, and horizontal to vertical controllers as $V, H, V H$, and $H V$, respectively. The vertical controller is designed for the main rotor and horizontal controller is designed for the tail rotor. $H V$ and $V H$ controllers are designed in order to cancel the coupling effect between two rotors represented by the bias in the tracking response.

The design of the assigned decoupling PDFLC for strong coupling and high nonlinear TRMS is shown in Figures 2, 3 , and 4 as a triangular membership function. Inputs for PDFLC are expressed by error and rate of the error while the output is the control signals. The linguistic variables of the two input membership functions for the four PDFLC are described as PL, P, PS, Z, NS, N, and NL. The input of PDFLC ranged from -0.5 to 0.5 for the horizontal part and from -0.6 to 0.6 for the other three PDFLCs while output of the four membership functions is PVL, PL, P, PS, Z, NS, N, NL, and NVL within range -2.5 to 2.5 . The linguistic variables are stated as PVL is positive very large, $\mathrm{PL}$ is positive large, $\mathrm{P}$ is positive, PS is positive small, $\mathrm{Z}$ is zero, NS is negative small, $\mathrm{N}$ is negative, NL is negative large, and NVL is negative very large.

Table 1 describes the rule base of the proposed PDFLC. Figure 5 shows the proposed controller of decoupling PDFLC. Ten gains will be tuned divided into eight gains for the proposed coupling PDFLC represented by four proportional gains and another four derivative gains in addition to two gains demonstrating the coupling effect from the output of $\mathrm{HV}$ and $\mathrm{VH}$ controllers.
TABLE 1: Rule base of all fuzzy controllers.

\begin{tabular}{lccccccc}
\hline$\Delta e \backslash e$ & NL & NM & NS & Z & PS & PM & PL \\
\hline NL & NVL & NVL & NL & NM & NS & NS & Z \\
N & NVL & NL & NM & NM & NS & Z & PS \\
NS & NL & NM & NS & NS & Z & PS & PM \\
Z & NM & NS & NS & Z & PS & PS & PM \\
PS & NM & NS & Z & PS & PS & PM & PL \\
P & NS & Z & PS & PM & PM & PL & PVL \\
PL & Z & PS & PS & PM & PL & PVL & PVL \\
\hline
\end{tabular}

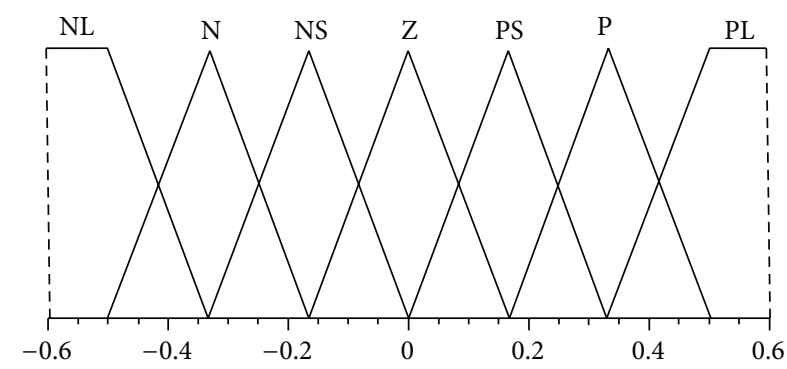

FIgURE 3: Membership fuctions of error and rate of vertical, vertical to horizontal, and horizontal to vertical fuzzy controllers.

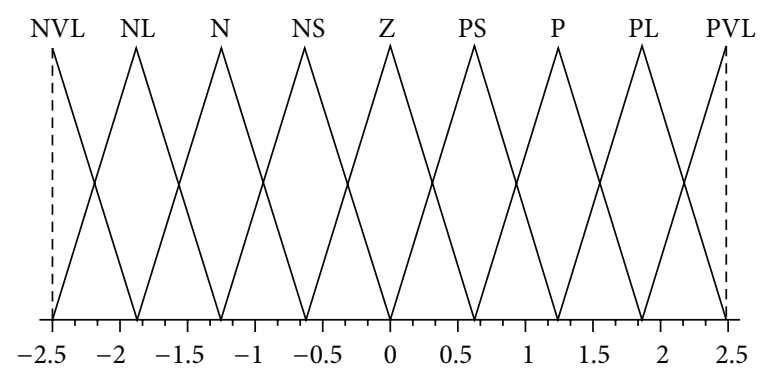

Figure 4: Membership functions of control signals of all fuzzy controllers.

3.2. Problem Formulation. Ten gains to be optimized are defined as KVe, KVde, KHe, KHde, KVHe, KVHde, KHVe, $K H V d e, K H V$, and $K V H$, where $K$ refers to gain, $V$ refers to vertical, $H$ refers to horizontal, $H V$ refers horizontal to vertical, $V H$ refers vertical to horizontal, $e$ refers to error, and de refers to rate of error. The gains assigned to be between maximum and minimum constraints as follows:

$$
\begin{gathered}
0.001 \leq K_{\text {fuzzy }}(i) \leq 40 \text { for } i=1, \ldots, 8 . \\
-2 \leq K_{\text {coupling }}(i) \leq 2 \text { for } i=1,2,
\end{gathered}
$$

where

$$
\begin{gathered}
K_{\text {fuzzy }} \\
=[K V e, K V d e, K H e, K H d e, K V H e, \\
K V H d e, K H V e, K H V d e]^{T}, \\
K_{\text {coupling }}=[K V H, K H V]^{T} .
\end{gathered}
$$




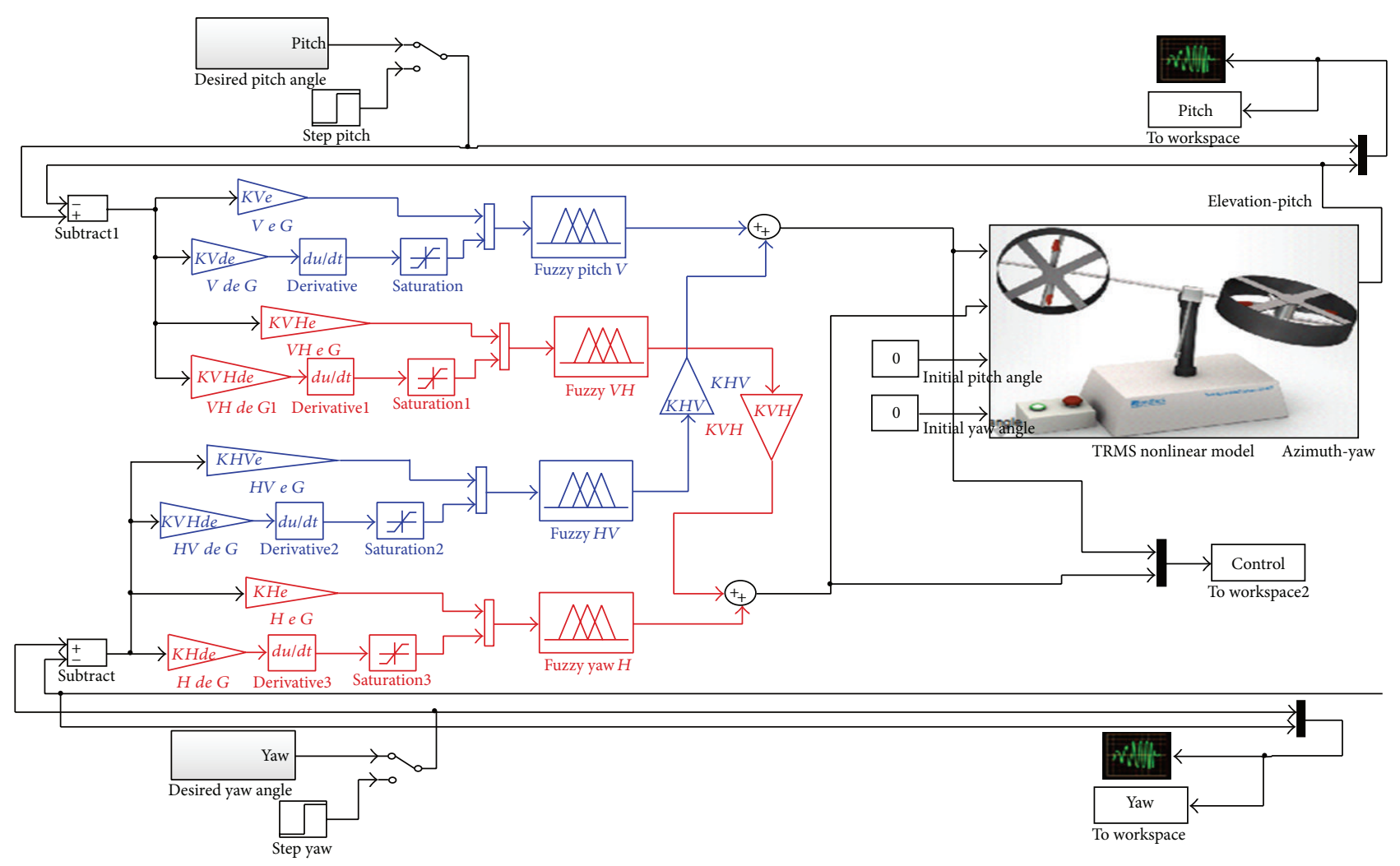

FIGURE 5: Proposed fuzzy controller for the nonlinear MIMO TRMS.

The objective function is chosen to satisfy well-tracked response as follows:

$$
\text { fit }=\sum_{t=0}^{t_{\text {sim }}}\left(e_{\psi}^{2}(t)+e_{\phi}^{2}(t)\right) \lambda(t),
$$

where

$$
\begin{aligned}
& e_{\psi}(t)=\psi_{d}(t)-\psi(t), \\
& e_{\phi}(t)=\phi_{d}(t)-\phi(t),
\end{aligned}
$$

$\psi(t)$ and $\psi_{d}(t)$, are actual and desired vertical angles, respectively, $\varphi(t)$ and $\varphi_{d}(t)$ are actual and desired horizontal angles, respectively, $e_{\psi}(t)$ and $e_{\varphi}(t)$ are errors between the desired and actual angles for vertical and horizontal parts respectively, and $\lambda(t)$ is a weight factor in order to penalize the error as time increases. Ten gains will be optimized using four optimization techniques as mentioned in the literature. The objective function of each optimization technique is a minimization function considering gains have to satisfy the constraints in (2). In this study, GSA, PSO, ABC, and DE will be developed as a comparison study in order to search for the optimal gains.

\section{Optimization Algorithms}

This work presents a comparison study among four evolutionary optimization techniques. Each optimization algorithm aims to find the optimal gains for minimum possible objective function as defined in (4). The following subsections describe briefly optimization techniques implemented in this work.

4.1. Gravitational Search Algorithm. In the last few years, gravitational search algorithm (GSA) has been introduced as a new metaheuristic optimization algorithm developed by newton gravitational laws and was first proposed in 2009 by [36]. The algorithm stated that, for any two objects, every object is attracted to the other object by attraction force which is directly proportional to their mass and inversely proportional to their square distance. GSA has been explained in detail in [36].

GSA can be summarized in the following flowchart as shown in Figure 6.

4.2. Particle Swarm Optimization. Particle swarm optimization has emerged recently as combinational metaheuristic approach and was first inspired from a behavior combined between bird flocking and fish schooling in 1995 by [22]. PSO combines principles of human sociocognition in addition to evolutionary computation. Each particle in the swarm represents a potential or a solution which is required to be sought in the search space in order to find the optimal solution. A potential is formed by a set of agents. Two important equations are necessary to emulate socio and cognition behaviors are represented by position and velocity 


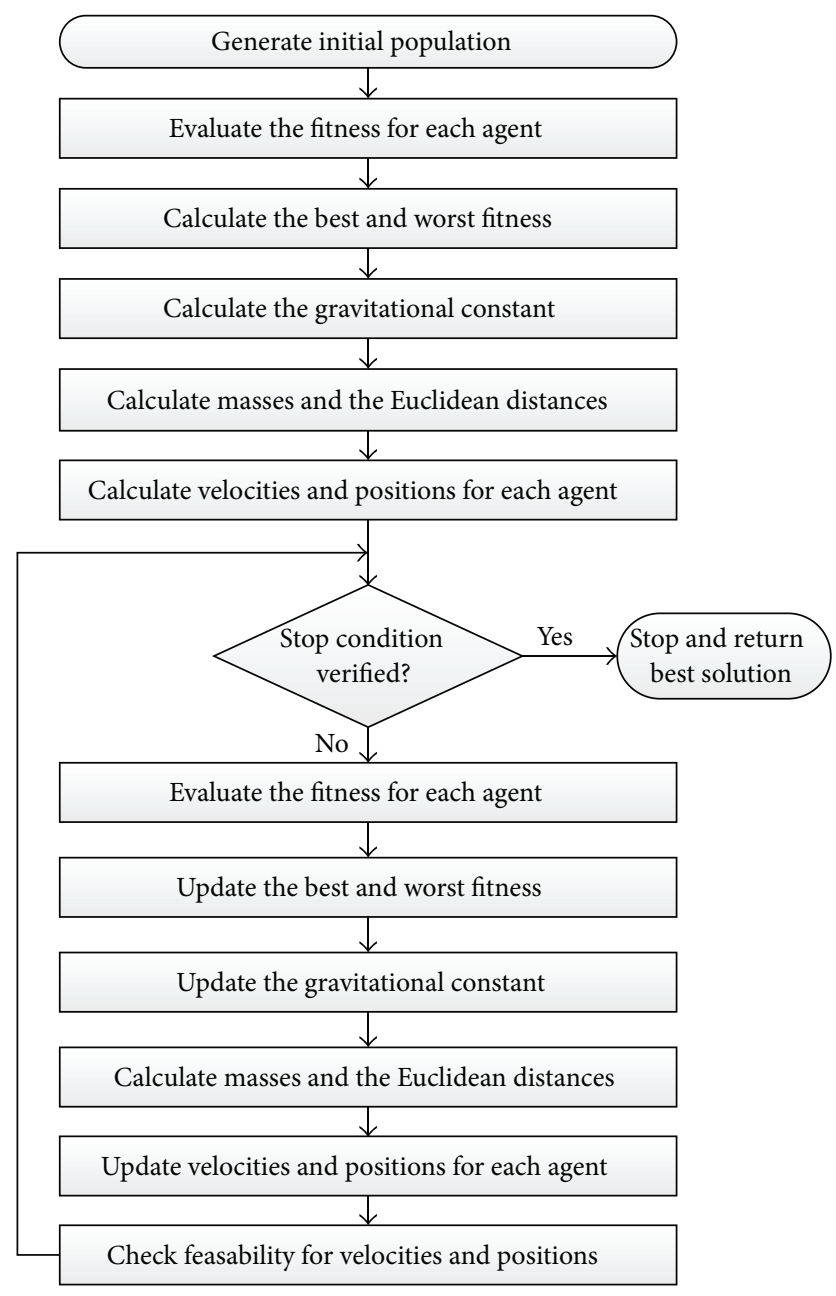

FIGURE 6: GSA computational flowchart.

for each agent. The position of the agent can be defined by the following equation:

$$
x_{i, j}(t)=v_{i, j}(t)+x_{i, j}(t-1) .
$$

The velocity of each agent can be defined by

$$
\begin{aligned}
v_{i, j}(t)= & \alpha(t) v_{i, j}(t-1)+c_{1} r_{1}\left(x_{i, j}^{*}(t-1)-x_{i, j}(t-1)\right) \\
& +c_{2} r_{2}\left(x_{i, j}^{* *}(t-1)-x_{i, j}(t-1)\right),
\end{aligned}
$$

where $i=1,2, \ldots, N$ and $N$ is the population size, $j=$ $1,2, \ldots, m$ and $m$ are the size of agents in the potential, $x_{i, j}^{*}$ is the local best solution, $x_{i, j}^{* *}$ is the global best solution, $\alpha(t)$ is a decreasing weight that can be defined by $\alpha(t)=$ $\exp (-\alpha(t-1) t), c_{1}$ and $c_{2}$ are positive constants, and $r_{1}$ and $r_{2}$ are uniformly distributed random numbers in $[0,1]$. PSO is described in detail in $[22,42]$.

PSO can be summarized in the following flowchart as shown in Figure 7.

4.3. Artificial Bees Colony. In the last few years, artificial bees colony has been introduced as a new metaheuristic

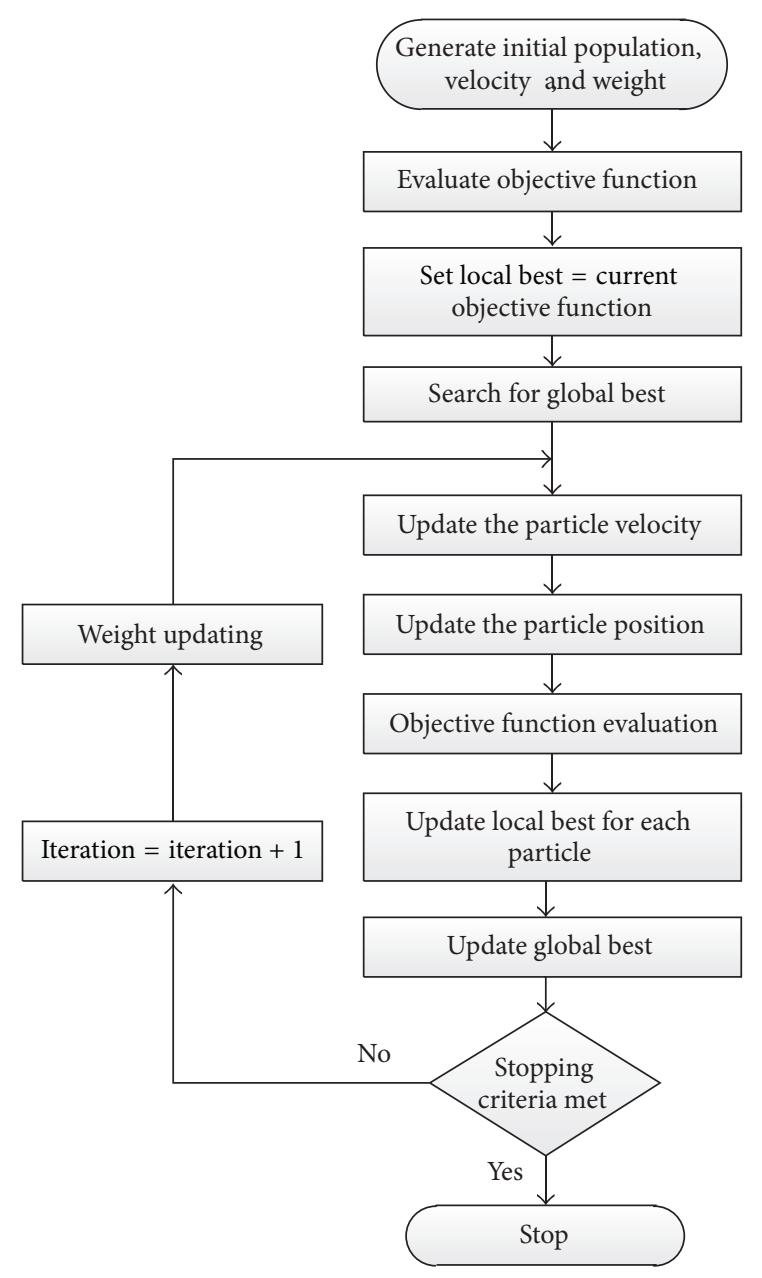

FIGURE 7: PSO computational flowchart.

optimization approach and was first inspired in 2005 by [32] Colony of bees usually divided into three groups of bees as employed, onlooker, and scout bees. Life in bees' colony can be briefly summarized as employed bees search randomly for food where the best position of food is considered as the optimal solution. Employed bees dance to share information with other bees about amount of nectar and food source. Onlookers wait in the hive to receive information from employed bees. Onlooker bees can differentiate between the good source and the bad source and decide on the food quality based on dance length, dance type, and speed of shaking. Onlooker bees choose scout bees before sending them for a new process of food searching. According to food quality, onlooker and scout bees may decide to be employed and vice versa. The relation between bees food searching and $\mathrm{ABC}$ has been discussed in detail in $[32,33]$. In the $\mathrm{ABC}$ algorithm employed and onlooker bees are responsible for searching in the space about the optimal solution while scout bees control the search process as mentioned in [33]. In ABC, the solution of the optimization problem is the position of the food source while the amount of nectar with respect to the quality refers to the objective function of the solution. 
The position of the food source in the search space can be described as follows:

$$
x_{i j}^{\text {new }}=x_{i j}^{\text {old }}+u\left(x_{i j}^{\text {old }}-x_{k j}\right) .
$$

The probability of onlooker bees for choosing a food source is as follows:

$$
p_{i}=\frac{\text { fitness }_{i}}{\sum_{i=1}^{E_{b}} \text { fitness }_{i}}
$$

with $i=1,2, \ldots, E_{b}$ and $E_{b}$ is the half of the colony size, $j=1,2, \ldots, D$, and $j$ is the number of positions with $D$ dimension, where $D$ refers to number of parameters to be defined, fitness ${ }_{i}$ is the fitness function, $k$ is a random number, where $k \in\left(1,2, \ldots, E_{b}\right)$, and $u$ is random number between 0 and 1 .

ABC can be summarized in the following flowchart as shown in Figure 8.

4.4. Differential Evolution. Differential evolution has been developed as an optimization technique and has been tested on "Chebyshev Polynomial fitting problem" before adding several improvements [27]. Finally, DE has been formulated as impressive optimization technique in [28]. DE has the same structure of Genetic algorithm represented by crossover and mutation in addition to retaining the better population and best solution by comparing the old population with the new one. Important relations will be used in the searching process represented by mutation and crossover. Performing mutation requires assigning mutation probability (MP) arbitrarily as a constant number between 0 and 1 . Mutation relation will be calculated only if MP is greater than a random number between 0 and 1 as follows:

$$
\begin{aligned}
V_{i}(G+1) \\
=X_{i}(G) \\
\quad+F\left(X_{\text {best }}(G)-X_{i}(G)\right)+F\left(X_{r_{1}}(G)-X_{r_{2}}(G)\right) .
\end{aligned}
$$

The crossover will be computed by simple relation where crossover probability (CP) will be set arbitrarily between 0 and 1 and then it will be compared to random number between 0 and 1 . The crossover step will be executed only if $\mathrm{CP}$ is greater than the random number. Crossover equation can be calculated from the following relation:

$$
X_{i}(G+1)=V_{i}(G+1) \text {, }
$$

where $i=1,2, \ldots, N_{p}$ and $i$ is iterated number for every solution in the generation, $X_{i}(G)$ represents a solution at iteration $i$ in the generation, $V_{i}(G+1)$ is a mutant vector generated from $(10), X_{r_{1}}(G), X_{r_{2}}(G)$ are solution vectors selected randomly from current generation, $X_{\text {best }}(G)$ is the best achieving solution, and $F$ is a random number between 0 and 1. DE is described in detail in [43].

$\mathrm{DE}$ can be summarized in the following flowchart as shown in Figure 9.

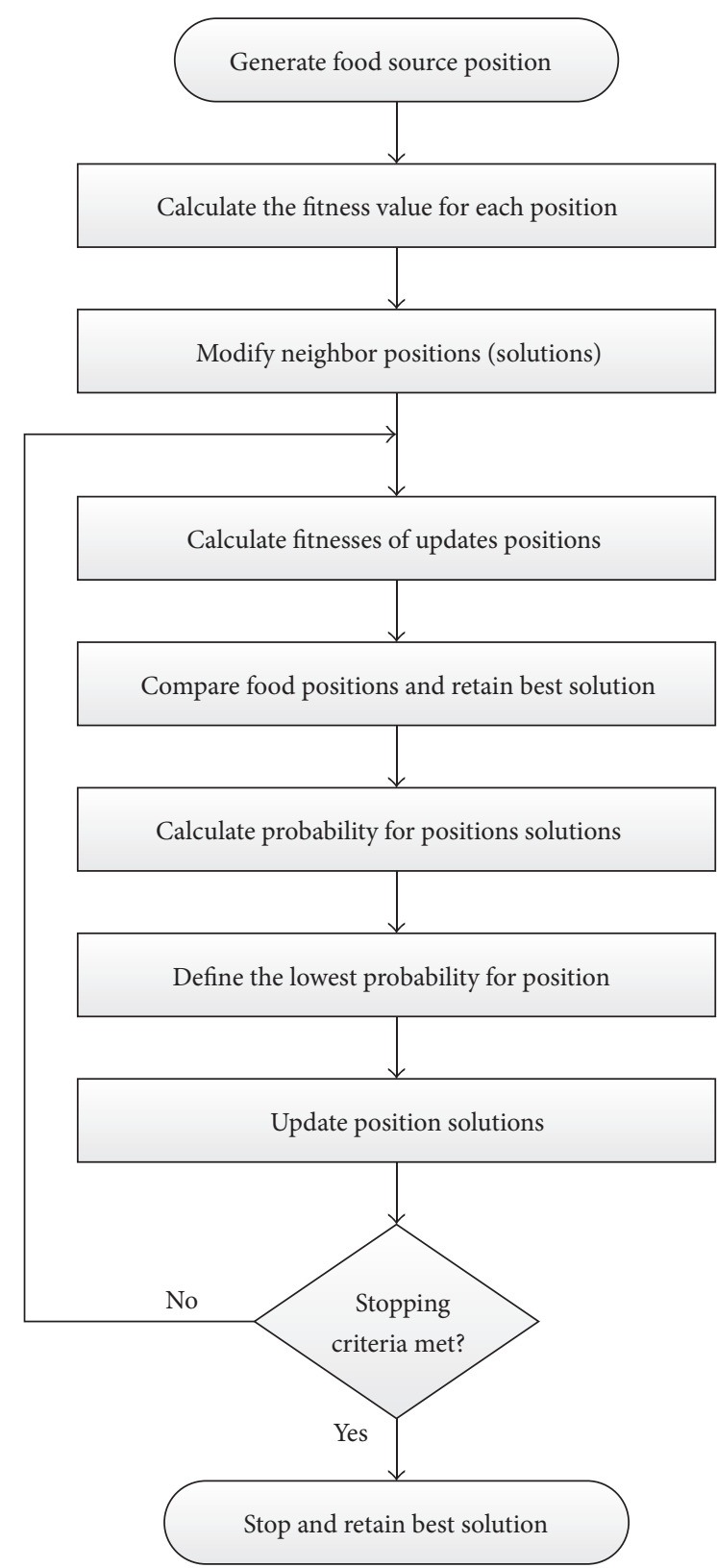

Figure 8: ABC computational flowchart.

4.5. Optimization Algorithms Implementation. For fair comparison, the population size is set as 150 particles for all techniques. For each particle, 10 parameters are defined to be optimized controller gains as shown in Figure 5. Initial settings for optimizations techniques are demonstrated in Tables 2, 3, and 4 for GSA, PSO, and DE, respectively, with setting maximum number of generations being 200 .

\section{Results and Discussions}

Nonlinear TRMS has been simulated considering TRMS parameters in The appendix. Briefly, the system has been simulated for 80 seconds with initial conditions for both pitch and yaw angles are 0.1 and $0.15 \mathrm{rad}$, respectively, with 0.01 


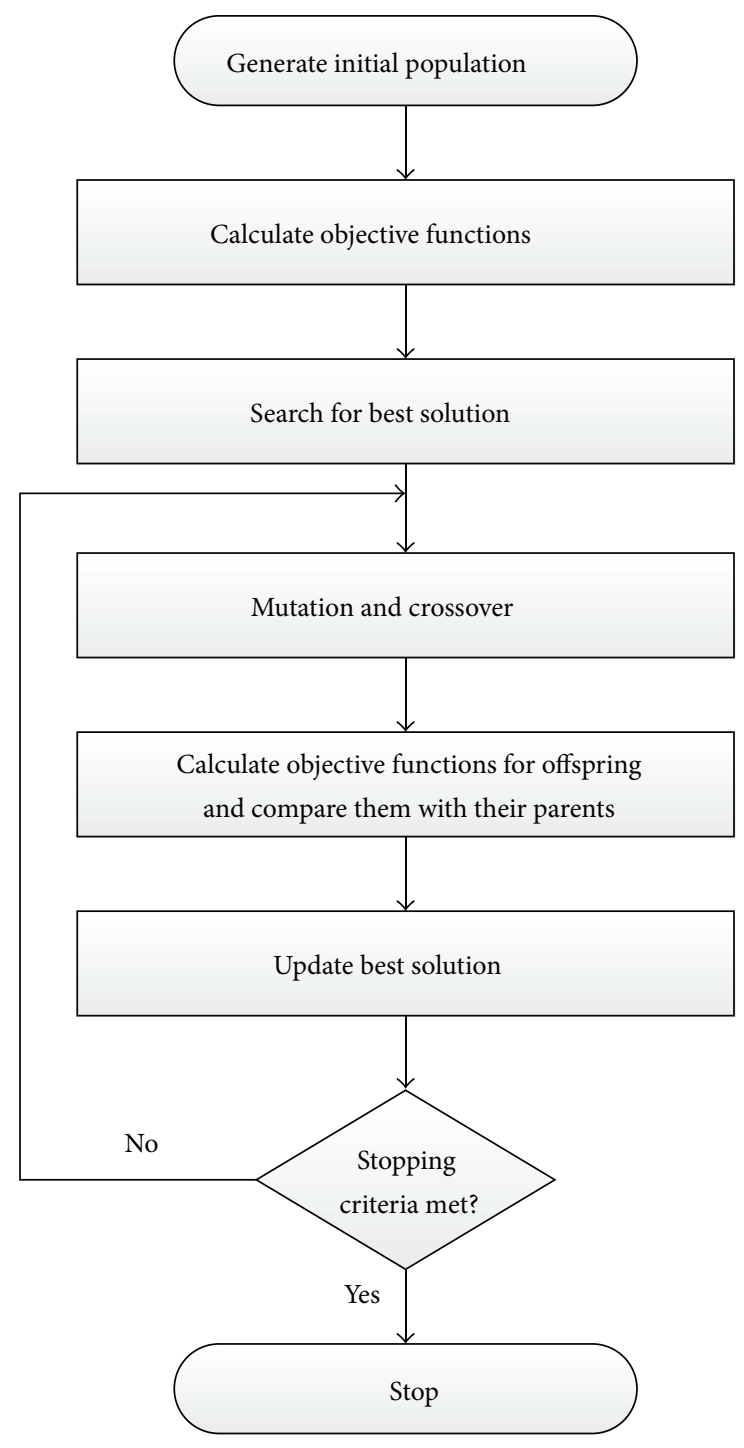

FIGURE 9: DE computational flowchart.

TABLE 2: Parameters setting for GSA.

\begin{tabular}{lccccc}
\hline Parameter & $\alpha$ & $\lambda$ & $\varepsilon$ & $G_{0}$ & $K_{\text {best }}$ \\
\hline Setting & 7 & 6 & 0.00001 & 1000 & 4 \\
\hline
\end{tabular}

TABle 3: Parameters setting for PSO.

\begin{tabular}{lcccc}
\hline Parameter & $\lambda$ & $\alpha$ & $c_{1}$ & $c_{2}$ \\
\hline Setting & 10 & 0.99 & 2 & 2 \\
\hline
\end{tabular}

seconds sampling time. The objective function is computed from (4) where $\lambda(t)$ is a penalty factor. To improve the settling time, the objective function will be multiplied by an increasing time weighting $\lambda(t)$ which starts initially as $\lambda(t)=$ 1. In this experiment, the reference has been chosen for both yaw and pitch angles to be $0.3 \sin (0.031 t)$.

GSA, PSO, ABC, and DE are functioned to search for minimum error for 80 iterations in a number of experiments
TABle 4: Parameters setting for DE.

\begin{tabular}{lccc}
\hline Parameter & MP & CP & $F$ \\
\hline Setting & 0.9 & 0.9 & 0.5 \\
\hline
\end{tabular}

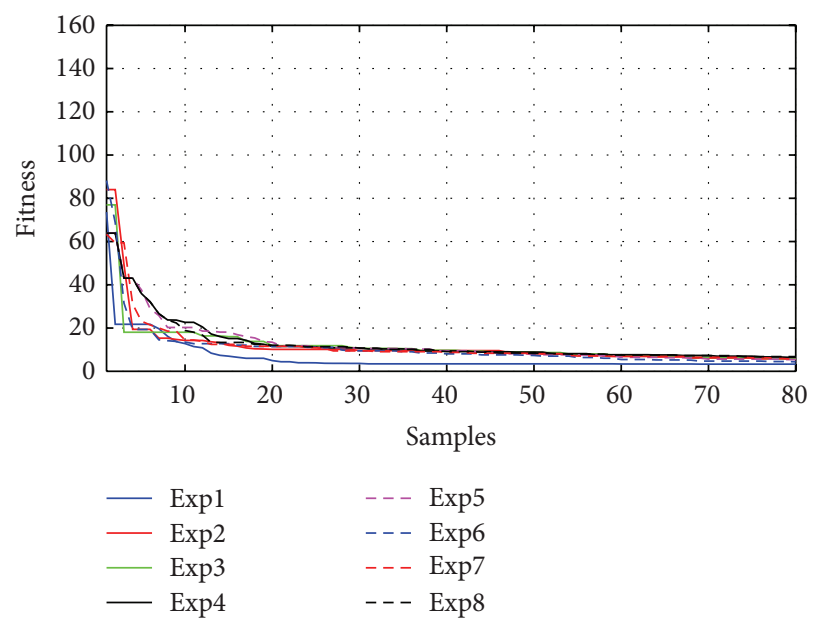

FIGURE 10: Fitness minimization for GSA with different initializations.

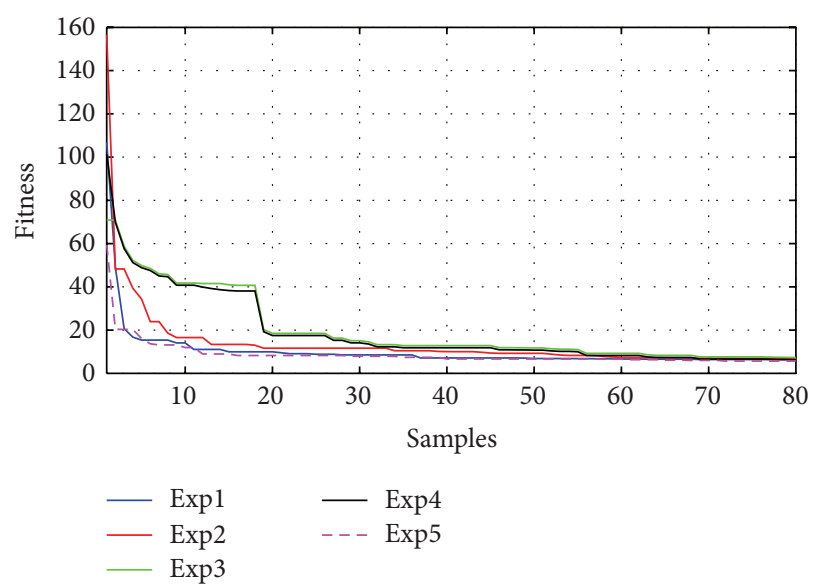

FIGURE 11: Fitness minimization for PSO with different initializations.

with different initializations. Table 5 demonstrates the minimum error after 80 iterations of each experiment and their average values with their consumption time per iteration and also the number of setting parameters is discussed. It is noticed from Table 5 that GSA has the smallest average followed by DE then PSO and the highest average is ABC although GSA has more setting parameters than other comparison techniques.

Figures 10-13 present the fitness reduction for GSA, $\mathrm{PSO}, \mathrm{ABC}$, and $\mathrm{DE}$, respectively, in 80 iterations. With different initial populations, GSA has been simulated in eight experiments while PSO, ABC, and DE have been simulated in five experiments in order to validate the robustness of the four search techniques. 
TABLE 5: Minimum error after 80 iterations and time per iteration.

\begin{tabular}{lccccccccccc}
\hline & Exp1 & Exp2 & Exp3 & Exp4 & Exp5 & Exp6 & Exp7 & Exp8 & Average & $\begin{array}{c}\text { Time per } \\
\text { iteration (sec) }\end{array}$ & $\begin{array}{c}\text { Setting } \\
\text { parameters }\end{array}$ \\
\hline GSA & 3.2915 & 5.7112 & 5.8316 & 6.4720 & 5.4030 & 4.3753 & 5.7497 & 6.7643 & 5.4498 & 6383.15 & 5 \\
PSO & 6.3411 & 6.9329 & 7.2922 & 6.293 & 5.6631 & - & - & - & 6.5045 & 6382.10 & 4 \\
ABC & 9.4855 & 11.5355 & 10.7622 & 9.9329 & 10.7004 & - & - & - & 10.4833 & 6382.60 & - \\
DE & 4.6437 & 7.8255 & 6.3855 & 6.4262 & 5.4983 & - & - & - & 6.1558 & 6381.44 \\
\hline
\end{tabular}

TABLE 6: Optimal gains after 200 iterations with their objective function.

\begin{tabular}{lccccccccccc}
\hline & KVe & KVde & KHVe & KHVde & KVHe & KVHde & KHe & KHde & KHV & KVH & Obj \\
\hline GSA & 40 & 26.544 & 40 & 29.2786 & 1.7778 & 20.8239 & 7.3525 & 2.2567 & -1.0862 & -0.6442 & 3.0380 \\
PSO & 39.95 & 21.117 & 39.8855 & 17.201 & 1.3643 & 22.7434 & 7.3525 & 13.9838 & -1.1284 & -1.0432 & 3.9698 \\
ABC & 35.5195 & 19.1465 & 25.3081 & 3.0515 & 4.3111 & 24.4751 & 19.5009 & 16.1338 & -1.2142 & -1.0412 & 7.5166 \\
DE & 40 & 26.4236 & 40 & 32.5652 & 1.2728 & 20.0212 & 4.3722 & 3.5919 & -1.0381 & -0.8021 & 3.2915 \\
\hline
\end{tabular}

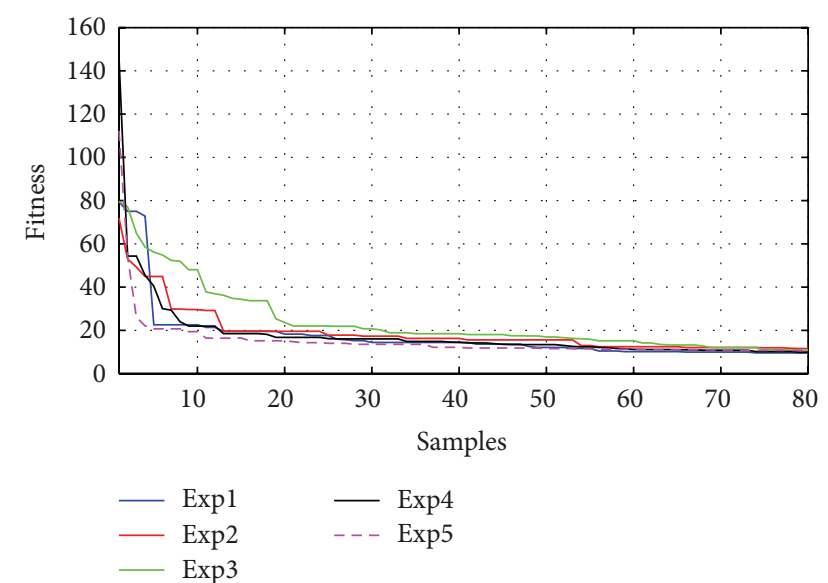

FIGURE 12: Fitness minimization for $\mathrm{ABC}$ with different initializations.

The robustness for each method has been validated as shown in Figures $10-13$ and Table 5 where the objective functions for each algorithm are very close by the end of 80 iterations. Figure 14 demonstrates the average fitness function for each algorithm.

The optimal gains of each search technique with their minimum objective function after 200 iterations are expressed in Table 6. After 200 iterations and among the four comparison techniques, GSA gives the minimum error. On contrary, $\mathrm{ABC}$ gives the highest error.

In order to validate the presented results in Table 6, two different scenarios discuss the proposed technique where the first case is nonzero initial condition with sinusoidal input and the second case is zero initial condition with sinusoidal transient response.

Case 1. Figure 15 shows the system response of the proposed fuzzy controller with initial conditions 0.1 and 0.15 for pitch and yaw angles, respectively. The reference input applied in this case is assigned to be $0.3 \sin (0.031 t)$ for both pitch and yaw angles. The output response shows that the error is almost

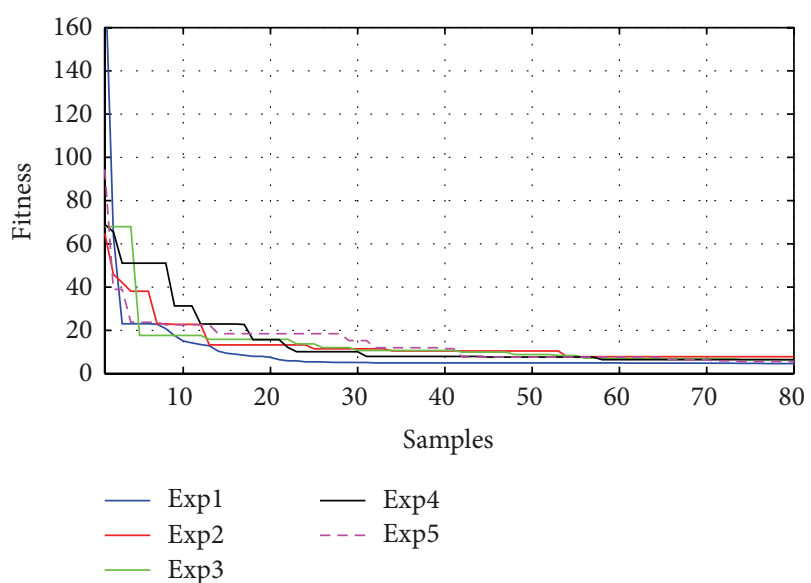

FIGURE 13: Fitness minimization for DE with different initializations.

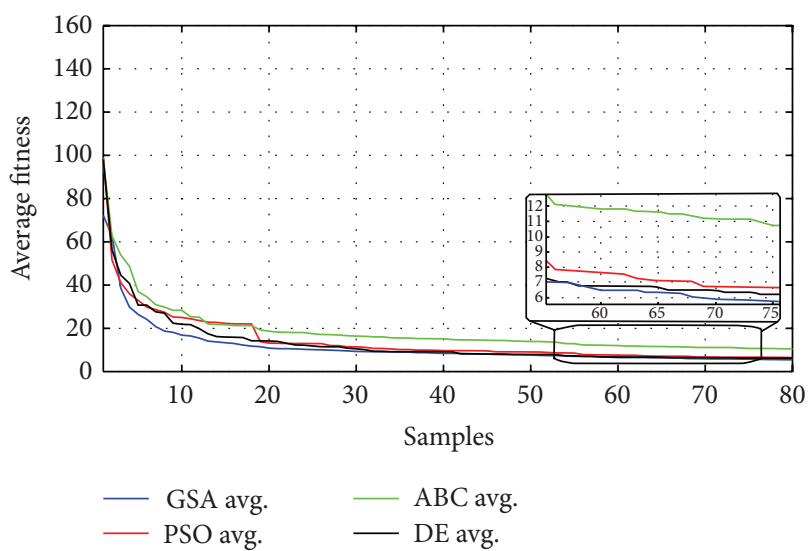

Figure 14: Average fitness for GSA, PSO, ABC, and DE.

zero which demonstrates the effectiveness of the proposed controllers. Focusing on the tracking response, GSA shows better tracking performance and closer to the reference signal followed by DE while ABC shows the farthest in addition to some ripples at the peak point. 

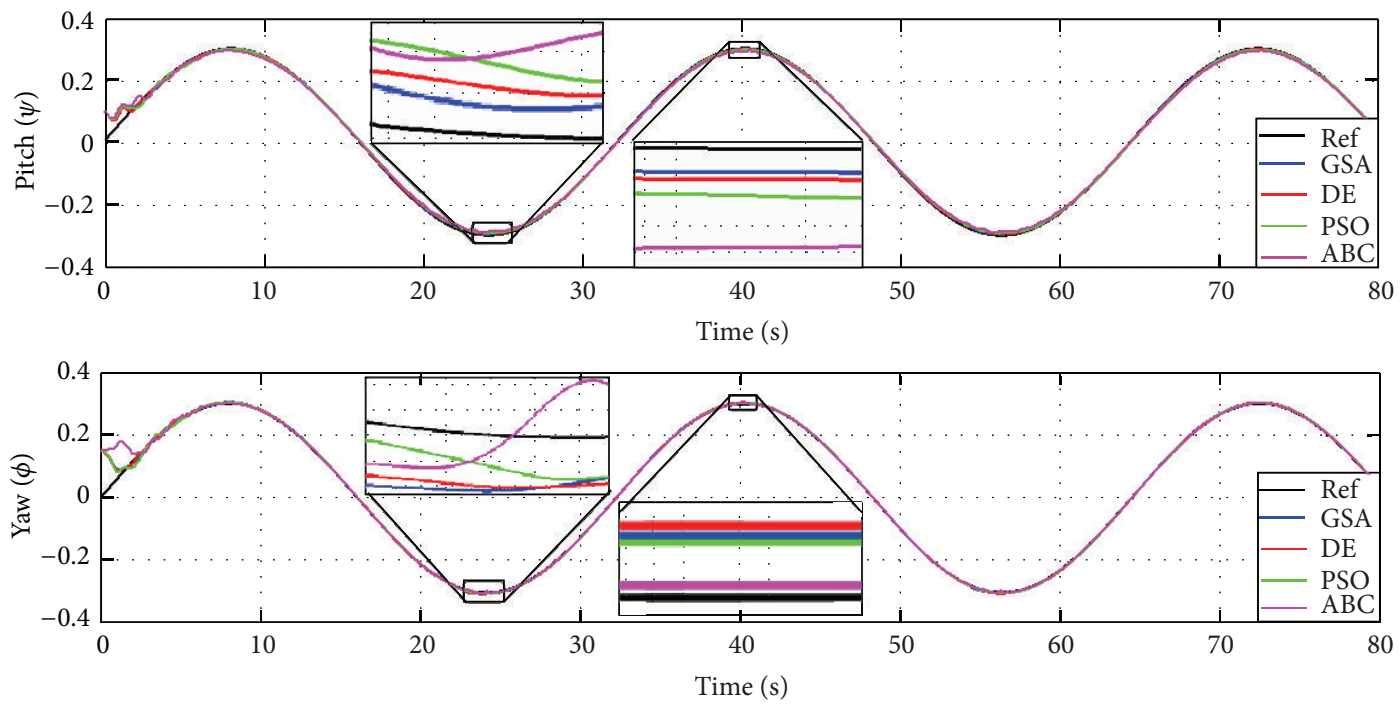

FIGURE 15: The proposed decoupling PDFLC controller response with GSA, PSO, ABC, and DE in Case 1.
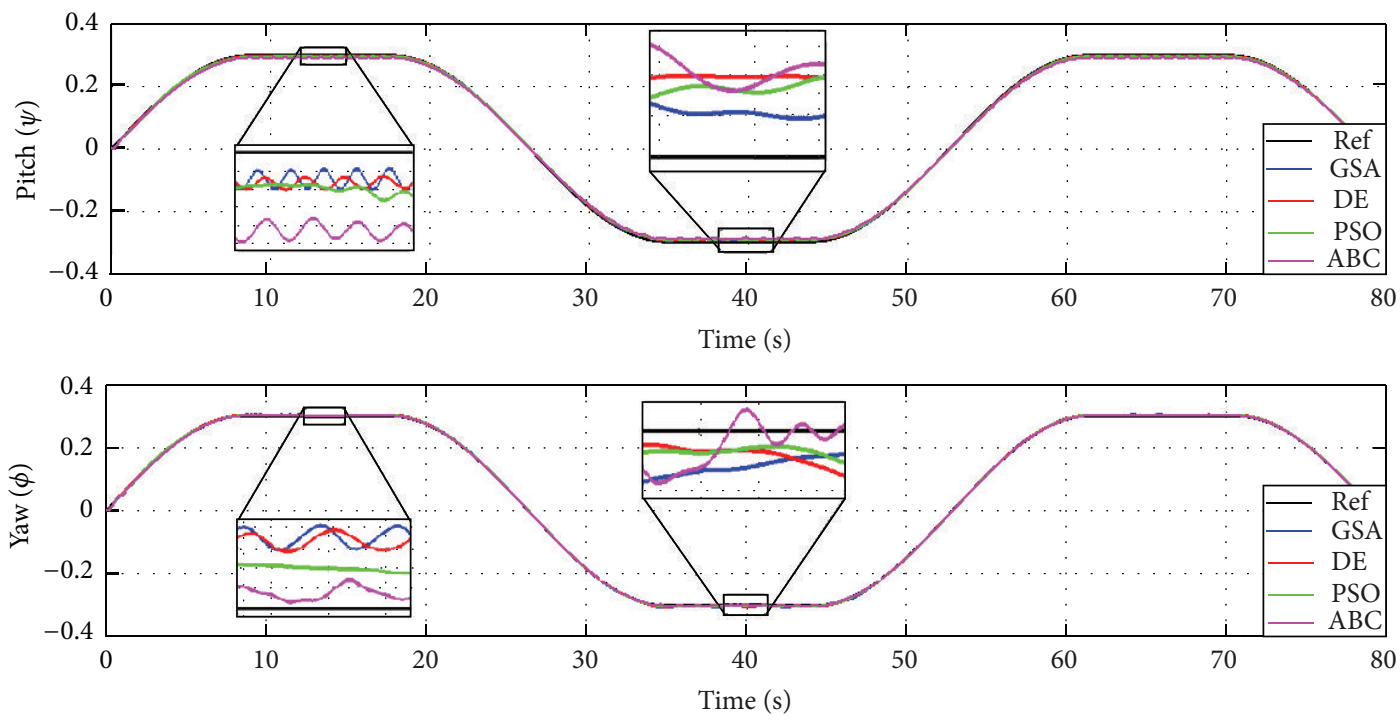

FIgURE 16: The proposed decoupling PDFLC controller response with GSA, PSO, ABC, and DE in Case 2.

Case 2. In this case, Figure 16 has square wave reference inputs with soft transients for both angles where the frequency is $0.023 \mathrm{~Hz}$. The output response shows good tracking results. Similar to Case 1, GSA shows close and well-tracked performance to the reference signal followed by $\mathrm{DE}$ in contrast to presence of ripples in $\mathrm{ABC}$ and a bit far from the reference input.

These two cases conclude that GSA is more robust and faster evolutionary algorithm in the search space than other three algorithms. Although four search algorithms give good tracking results with the proposed controller PDFLC, GSA is the most impressive technique with minimum objective function.

\section{Conclusion}

In this work, a comprehensive comparative study of four optimization techniques with decoupling PDFLC for high nonlinear TRMS has been proposed in order to cancel high nonlinearities and to solve high coupling effects in addition to maintaining the control signal within a suitable range. GSA, PSO, ABC, and DE have been implemented to tune the controller parameters and they showed great results in terms of tracking and error minimization. Robustness has been validated successfully for each technique with different initializations, optimizing the control parameters attempted by the optimization algorithms with two different operating conditions to test the efficacy of each algorithm. Finally, 
TABLE 7: TRMS parameters.

\begin{tabular}{lccc}
\hline Parameters description & Parameter value & Parameters description & Parameter value \\
\hline$I_{1} \mathrm{~kg} \cdot \mathrm{m}^{2}$ & $6.8 \times 10^{-2}$ & $a_{1}$ & 0.0135 \\
$I_{2} \mathrm{~kg} \cdot \mathrm{m}^{2}$ & $2 \times 10^{-2}$ & $b_{1}$ & 0.0924 \\
$B_{1 \psi}(\mathrm{N} \cdot \mathrm{m} \cdot \mathrm{sec} / \mathrm{rad})$ & $6 \times 10^{-3}$ & $a_{2}$ & 0.02 \\
$B_{2 \psi}(\mathrm{N} \cdot \mathrm{m} \cdot \mathrm{sec} / \mathrm{rad})$ & $1 \times 10^{-3}$ & $b_{2}$ & 0.09 \\
$B_{1 \varphi}(\mathrm{N} \cdot \mathrm{m} \cdot \mathrm{sec} / \mathrm{rad})$ & 0.1 & $k_{1}$ & 1.1 \\
$B_{2 \varphi}(\mathrm{N} \cdot \mathrm{m} \cdot \mathrm{sec} / \mathrm{rad})$ & 0.01 & $k_{2}$ & 0.8 \\
$K_{g y}(\mathrm{rad} / \mathrm{sec})$ & 0.5 & $T_{11}$ & 1.1 \\
$M_{g}(\mathrm{~N} \cdot \mathrm{m})$ & 0.32 & $T_{10}$ & 1 \\
$T_{22}$ & 1 & $T_{20}$ & 1 \\
\hline
\end{tabular}

GSA shows the most impressive results in contrast to other algorithms with respect to convergence speed and optimum objective function. Implementing gain-scheduling technique with the decoupling PD fuzzy controller can be considered as a recommended future work.

\section{Appendix}

The parameters of the twin rotor MIMO system used in this study are given as shown in Table 7.

\section{Conflict of Interests}

The authors declare that there is no conflict of interests regarding the publication of this paper.

\section{Acknowledgment}

The authors acknowledge the support of Deanship of Scientific Research, King Fahd University of Petroleum and Minerals, through the Electrical Power and Energy Systems Research Group Project no. RG1303-1\&2.

\section{References}

[1] Feedback, Twin Rotor MIMO System User Manual, 1998.

[2] S. F. Toha and M. O. Tokhi, "Real-coded genetic algorithm for parametric modelling of a TRMS," in Proceedings of the IEEE Congress on Evolutionary Computation (CEC '09), pp. 20222028, May 2009.

[3] S. F. Toha, I. Abd Latiff, M. Mohamad, and M. O. Tokhi, "Parametric modelling of a TRMS using dynamic spread factor particle swarm optimisation," in Proceedings of the 11th International Conference on Computer Modelling and Simulation (UKSIM '09), pp. 95-100, March 2009.

[4] S. M. Ahmad, M. H. Shaheed, A. J. Chipperfield, and M. O. Tokhi, "Nonlinear modelling of a twin rotor MIMO system using radial basis function networks," in Proceedings of the IEEE National Aerospace and Electronics Conference (NAECON '00), pp. 313-320, October 2000.

[5] J.-G. Juang, M.-T. Huang, and W.-K. Liu, "PID control using presearched genetic algorithms for a MIMO system," IEEE Transactions on Systems, Man and Cybernetics Part C: Applications and Reviews, vol. 38, no. 5, pp. 716-727, 2008.
[6] P. Wen and T.-W. Lu, "Decoupling control of a twin rotor MIMO system using robust deadbeat control technique," IET Control Theory \& Applications, vol. 2, no. 11, pp. 999-1007, 2008.

[7] A. Rahideh and M. H. Shaheed, "Robust model predictive control of a twin rotor MIMO system," in Proceedings of the IEEE 2009 International Conference on Mechatronics (ICM 09), pp. 1-6, April 2009.

[8] M. López-Martínez, C. Vivas, and M. G. Ortega, "A multivariable nonlinear Ho controller for a laboratory helicopter," in Proceedings of the 44th IEEE Conference on Decision and Control, and the European Control Conference (CDC-ECC '05), pp. 4065-4070, December 2005.

[9] T.-S. Kim, J.-H. Yang, Y.-S. Lee, and O.-K. Kwon, "Twin rotors system modeling and bumpless transfer implementation algorithm for LQ control," in Proceedings of the SICE-ICASE International Joint Conference, pp. 114-119, October 2006.

[10] A. Rahideh and M. H. Shaheed, "Hybrid fuzzy-PID-based control of a twin rotor MIMO system," in Proceedings of the 32nd Annual Conference on IEEE Industrial Electronics (IECON '06), pp. 49-54, November 2006.

[11] S. F. Toha and M. O. Tokhi, "Dynamic nonlinear inverse-model based control of a twin rotor system using adaptive neuro-fuzzy inference system," in Proceedings of the 3rd UKSim European Modelling Symposium on Computer Modelling and Simulation (EMS '09), pp. 107-111, November 2009.

[12] C.-W. Tao, J.-S. Taur, Y.-H. Chang, and C.-W. Chang, "A novel fuzzy-sliding and fuzzy-integral-sliding controller for the twinrotor multi-inputmulti-output system," IEEE Transactions on Fuzzy Systems, vol. 18, no. 5, pp. 893-905, 2010.

[13] S. Mondal and C. Mahanta, "Adaptive second-order sliding mode controller for a twin rotor multi-input-multi-output system," IET Control Theory \& Applications, vol. 6, no. 14, pp. 2157-2167, 2012.

[14] Y. Li, S. Tong, Y. Liu, and T. Li, "Adaptive fuzzy robust output feedback control of nonlinear systems with unknown dead zones based on a small-gain approach," IEEE Transactions on Fuzzy Systems, vol. 22, no. 1, pp. 164-176, 2014.

[15] S. Tong and Y. Li, "Adaptive fuzzy output feedback control of MIMO nonlinear systems with unknown dead-zone inputs," IEEE Transactions on Fuzzy Systems, vol. 21, no. 1, pp. 134-146, 2013.

[16] F. Zheng, Q.-G. Wang, and T. H. Lee, "Output tracking control of MIMO fuzzy nonlinear systems using variable structure control approach," IEEE Transactions on Fuzzy Systems, vol. 10, no. 6, pp. 686-697, 2002.

[17] S. Tong, X. He, Y. Li, and H. Zhang, "Adaptive fuzzy backstepping robust control for uncertain nonlinear systems based on 
small-gain approach," Fuzzy Sets and Systems, vol. 161, no. 6, pp. 771-796, 2010.

[18] I. Pan, S. Das, and A. Gupta, "Tuning of an optimal fuzzy PID controller with stochastic algorithms for networked control systems with random time delay," ISA Transactions, vol. 50, no. 1, pp. 28-36, 2011.

[19] D. K. Saroj and I. Kar, "T-S fuzzy model based controller and observer design for a Twin Rotor MIMO System," in Proceedings of the IEEE International Conference on Fuzzy Systems (FUZZ '13), pp. 1-8, July 2013.

[20] S.-C. Tong, Y.-M. Li, G. Feng, and T.-S. Li, "Observer-based adaptive fuzzy backstepping dynamic surface control for a class of MIMO nonlinear systems," IEEE Transactions on Systems, Man, and Cybernetics, Part B: Cybernetics, vol. 41, no. 4, pp. 1124-1135, 2011.

[21] Y. Li, S. Tong, and T. Li, "Observer-based adaptive fuzzy tracking control of MIMO stochastic nonlinear systems with unknown control direction and unknown dead-zones," IEEE Transactions on Fuzzy Systems, vol. PP, no. 99, p. 1, 2014.

[22] R. C. Eberhart and J. Kennedy, "New optimizer using particle swarm theory," in Proceedings of the 6th International Symposium on Micro Machine and Human Science, pp. 39-43, October 1995.

[23] K.-B. Lee and J.-H. Kim, "Multiobjective particle swarm optimization with preference-based sort and its application to path following footstep optimization for humanoid robots," IEEE Transactions on Evolutionary Computation, vol. 17, no. 6, pp. 755-766, 2013.

[24] Z.-L. Gaing, "A particle swarm optimization approach for optimum design of PID controller in AVR system," IEEE Transactions on Energy Conversion, vol. 19, no. 2, pp. 384-391, 2004.

[25] V. Mukherjee and S. P. Ghoshal, "Intelligent particle swarm optimized fuzzy PID controller for AVR system," Electric Power Systems Research, vol. 77, no. 12, pp. 1689-1698, 2007.

[26] C.-F. Juang and Y.-C. Chang, "Evolutionary-group-based particle-swarm-optimized fuzzy controller with application to mobile-robot navigation in unknown environments," IEEE Transactions on Fuzzy Systems, vol. 19, no. 2, pp. 379-392, 2011.

[27] R. Storn and K. Price, Differential Evolution-A Simple and Efficient Adaptive Scheme for Global Optimization Over Continuous Spaces, International Computer Science InstituteDirections, Berkeley, Calif, USA, 1995.

[28] R. Storn and K. Price, "Differential evolution-a simple and efficient heuristic for global optimization over continuous spaces," Journal of Global Optimization, vol. 11, no. 4, pp. 341359, 1997.

[29] L. D. S. Coelho and M. W. Pessôa, "A tuning strategy for multivariable PI and PID controllers using differential evolution combined with chaotic Zaslavskii map," Expert Systems with Applications, vol. 38, no. 11, pp. 13694-13701, 2011.

[30] N. Salvatore, A. Caponio, F. Neri, S. Stasi, and G. L. Cascella, "Optimization of delayed-state kalman-filter-based algorithm via differential evolution for sensorless control of induction motors," IEEE Transactions on Industrial Electronics, vol. 57, no. 1, pp. 385-394, 2010.

[31] C.-H. Chen, C.-L. Lin, and C.-T. Lin, "Nonlinear system control using adaptive neural fuzzy networks based on a modified differential evolution," IEEE Transactions on Systems, Man and Cybernetics Part C: Applications and Reviews, vol. 39, no. 4, pp. 459-473, 2009.
[32] D. Karaboga, "An idea based on honey bee swarm for numerical optimization," Tech. Rep. tr06, Department of Computer Engineering, Faculty of Engineering, Erciyes University, 2005.

[33] D. Karaboga and B. Basturk, "A powerful and efficient algorithm for numerical function optimization: artificial bee colony (ABC) algorithm," Journal of Global Optimization, vol. 39, no. 3, pp. 459-471, 2007.

[34] F. S. Abu-Mouti and M. E. El-Hawary, "Optimal distributed generation allocation and sizing in distribution systems via artificial bee colony algorithm," IEEE Transactions on Power Delivery, vol. 26, no. 4, pp. 2090-2101, 2011.

[35] W.-L. Chang, D. Zeng, R.-C. Chen, and S. Guo, "An artificial bee colony algorithm for data collection path planning in sparse wireless sensor networks," International Journal of Machine Learning and Cybernetics, 2013.

[36] E. Rashedi, H. Nezamabadi-pour, and S. Saryazdi, "GSA: a Gravitational Search Algorithm," Information Sciences, vol. 179, no. 13, pp. 2232-2248, 2009.

[37] A. Ghasemi, H. Shayeghi, and H. Alkhatib, "Robust design of multimachine power system stabilizers using fuzzy gravitational search algorithm," International Journal of Electrical Power \& Energy Systems, vol. 51, pp. 190-200, 2013.

[38] R.-E. Precup, R.-C. David, E. M. Petriu, S. Preitl, and M.B. Radac, "Novel adaptive gravitational search algorithm for fuzzy controlled servo systems," IEEE Transactions on Industrial Informatics, vol. 8, no. 4, pp. 791-800, 2012.

[39] A. Bhattacharya and P. K. Roy, "Solution of multi-objective optimal power flow using gravitational search algorithm," IET Generation, Transmission \& Distribution, vol. 6, no. 8, pp. 751$763,2012$.

[40] T. Niknam, M. R. Narimani, R. Azizipanah-Abarghooee, and B. Bahmani-Firouzi, "Multiobjective optimal reactive power dispatch and voltage control: a new opposition-based selfadaptive modified gravitational search algorithm," IEEE Systems Journal, vol. 7, no. 4, pp. 742-753, 2013.

[41] L. A. Zadeh, "Fuzzy sets," Information and Computation, vol. 8, pp. 338-353, 1965.

[42] M. A. Abido, "Optimal power flow using particle swarm optimization," International Journal of Electrical Power and Energy Systems, vol. 24, no. 7, pp. 563-571, 2002.

[43] A. A. A. E. Ela, M. A. Abido, and S. R. Spea, "Differential evolution algorithm for optimal reactive power dispatch," Electric Power Systems Research, vol. 81, no. 2, pp. 458-464, 2011. 

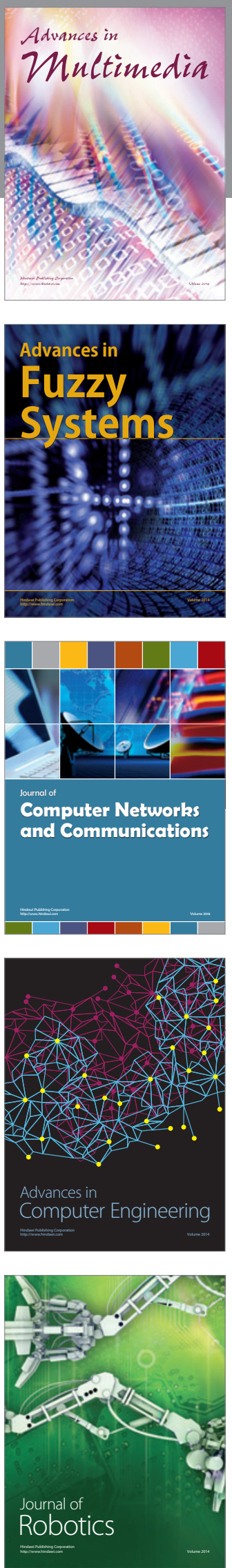

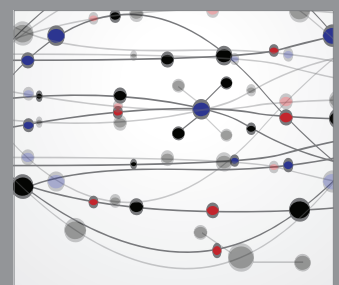

The Scientific World Journal
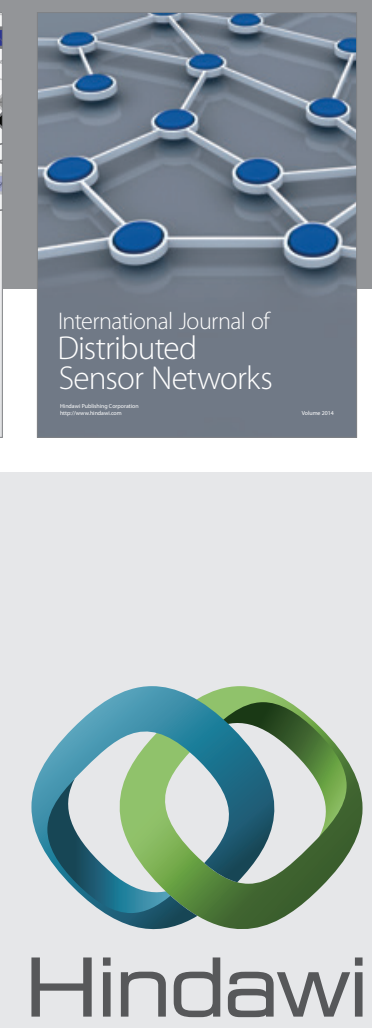

Submit your manuscripts at

http://www.hindawi.com
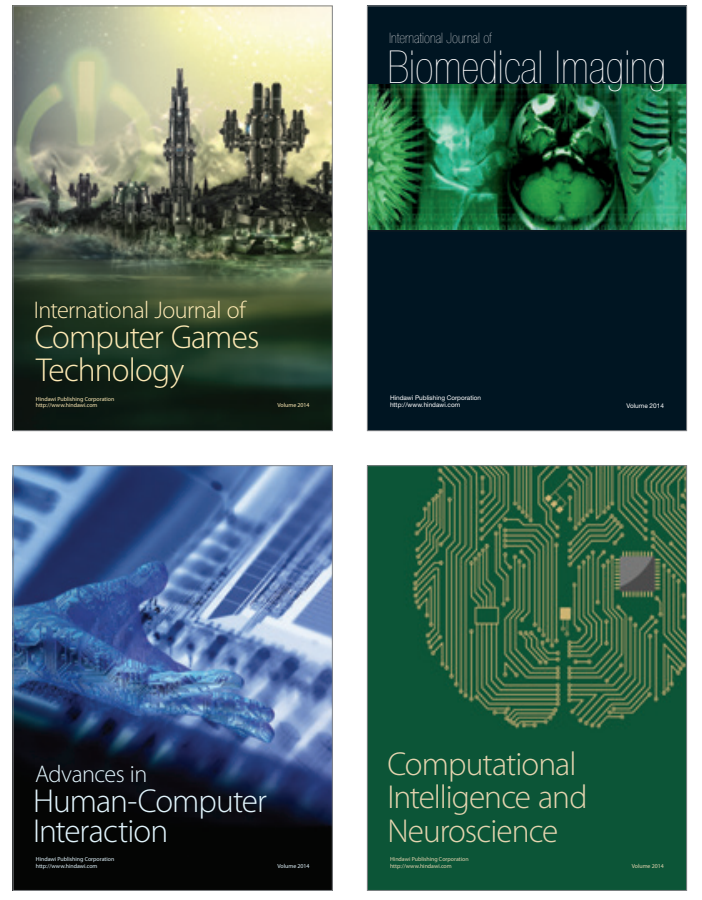
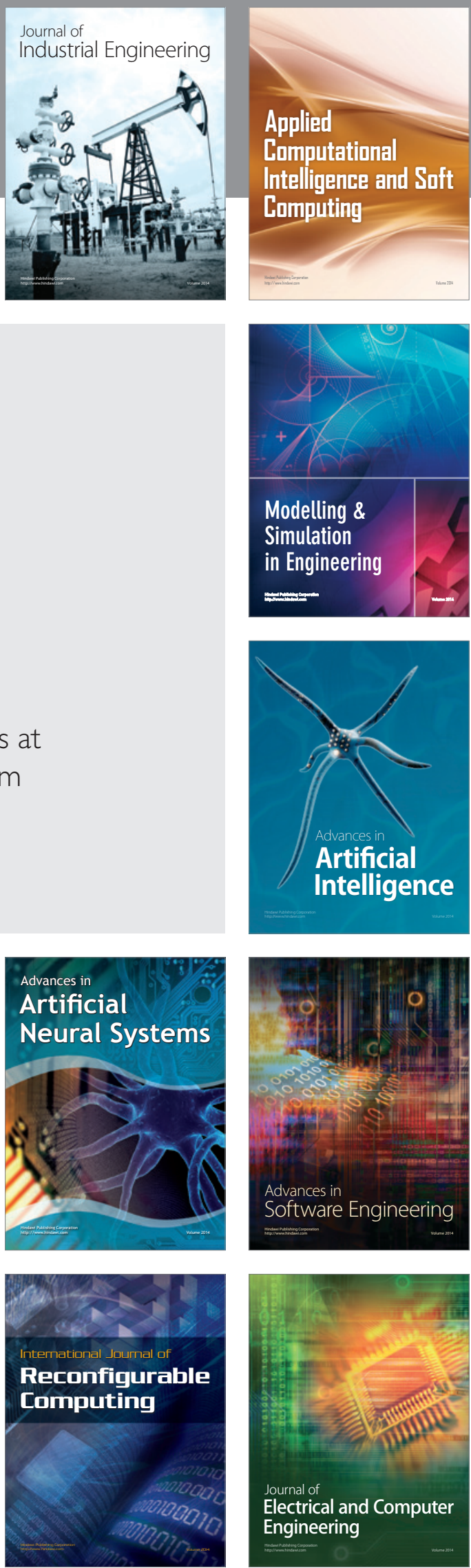